\author{
Military Technical College \\ Kobry El-Kobbah, \\ Cairo, Egypt.
}

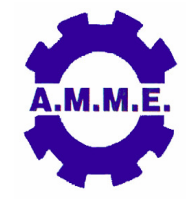

\author{
$15^{\text {th }}$ International Conference \\ on Applied Mechanics and \\ Mechanical Engineering.
}

\title{
CALIBRATION OF THE HYSTERESIS LOOP OF SMA WIRES HEATED BY ELECTRIC CURRENT
}

\author{
M. Fouda*, M. Tawfik ${ }^{\star *}$ and G. Elbayoumi ${ }^{\star \star *}$
}

\begin{abstract}
The undesirable vibrations in all structures types (buildings, vehicles, machines and electronics) affect the durability, performance and the control of these structures. Damping of these vibrations is the concern of many researches using smart materials. The super-elastic behavior of shape memory alloys (SMA) may be utilized in the active damping of structures vibrations.
\end{abstract}

SMA wire was obtained for this research but we had to calibrate it to get loadelongation-heat relations. In the process of SMA calibrating, an experimental device was designed to measure different loadings and the corresponding elongations at different heating conditions. To control the temperature an electric direct current was used.

The obtained experimental results were similar to the results in several published researches. The relation between the electric current and the crystal transformation of SMA under different loadings is well defined. Clear stress-strain curves showing the hysteresis loop at different current values were obtained.

\section{KEY WORDS}

Shape Memory Alloy, Pseudo-elasticity, Vibration, Active Control, and Smart Materials.

Graduate student, Dept. of Aerospace Eng., Cairo University.

Email: moatasemfouda@gmail.com.

** Associate professor of aircraft structures, Dept. of Aerospace Eng., Cairo University.

Email: mohammad.tawfik@gmail.com

*** Professor of aircraft control and guidance, Dept. of Aerospace Eng., Cairo University.

Email: gelbayoumi@yahoo.com 


\section{NOMENCLATURE}

$\begin{array}{ll}\varepsilon & \text { Engineering strain } \\ \sigma & \text { Engineering stress } \\ \sigma_{y} & \text { Yield stress } \\ A_{A s} & \text { Austenite start current } \\ A_{A f} & \text { Austenite finish current } \\ A_{M s} & \text { Martensite start current } \\ A_{M f} & \text { Martensite finish t current } \\ D_{A} & \text { Current-activated wire diameter }(\mathrm{mm}) \\ D_{\circ} & \text { Original wire diameter (mm) } \\ E_{A} & \text { Young's modulus of the austenite phase } \\ E_{A M} & \text { Young's modulus of the austenite to martensite transformation phase } \\ E_{M} & \text { Young's modulus of the martensite phase } \\ E_{M A} & \text { Young's modulus of the martensite to austenite transformation phase } \\ \mathrm{F} & \text { Axial load on SMA wire (grams) } \\ L_{A} & \text { Current-activated length (mm) } \\ L_{\circ} & \text { Original length (mm) } \\ g & \text { Gravitational acceleration } 9.81 \mathrm{~m} / \mathrm{s}^{2} \\ \mathrm{~T}_{\mathrm{As}} & \text { Austenite start temperature } \\ \mathrm{T}_{\mathrm{Af}} & \text { Austenite finish temperature } \\ \mathrm{T}_{\mathrm{Ms}} & \text { Martensite start temperature } \\ \mathrm{T}_{\mathrm{Mf}} & \text { Martensite finish temperature }\end{array}$

\section{INTRODUCTION}

Shape memory alloys are the materials that posses the ability to change shape via extension, bending, or twisting and then recover the deformation, returning to the original pre-selected-shape upon heat activation. These alloys are capable of sustaining and recovering relatively large strains (about 8\%) without undergoing plastic deformation. Another important characteristic is the energy dissipation in SMA due to the property of elastic hysteresis, the difference between the stress-strain curve in the loading and unloading case. The elastic hysteresis comes from the material's ability to undergo internal crystalline transformations in the presence of external applied stress and/or changes in temperature [1].

There are many alloys that have shape memory effect which was discovered first by Chang and Read [2] in Au-Cd alloy. Ni-Ti alloys, which discovered by Buehler et al [3], showed high tensile strength and high dissipating capability for the structural vibrations energy [4].

SMA was used as a passive structural damping element in many researches [5][6]. Our research in the field of "Active control of structural vibrations" utilized the property of energy dissipation of the Ni-Ti SMA by controlling the amount of the dissipated energy using an electrical current. We acquired SMA wire from DYNALLOY, INC with the following specifications: 


$\begin{array}{ll}\text { Model: } & \mathrm{FLEXINOL}^{\circledR} \\ \text { Material: } & \text { Nickel - Titanium alloy (Nitinol) } \\ \text { Diameter: } & 0.1 \mathrm{~mm} \\ \text { Density: } & 6.45 \mathrm{~g} / \mathrm{cm}^{3} \\ \text { Specific Heat: } & 0.2 \mathrm{cal} / \mathrm{g}{ }^{*} \mathrm{C} \\ \text { Melting Point: } & 1300{ }^{\circ} \mathrm{C} \\ T_{\text {As: }}: & 70{ }^{\circ} \mathrm{C} \\ \text { Latent Heat of Transformation: } & 5.78 \mathrm{cal} / \mathrm{g} \\ \text { Thermal Conductivity: } & 0.18 \mathrm{~W} / \mathrm{cm} *{ }^{\circ} \mathrm{C} \\ \text { Thermal Expansion Coefficient: } & \text { Martensite: } 6.6 \times 10^{-6} /{ }^{\circ} \mathrm{C} \\ & \text { Austenite: } 11.0 \times 10^{-6} /{ }^{\circ} \mathrm{C}\end{array}$

We needed to test the material to get the stress-strain relations and the hysteresis loop behavior with different temperatures. These different temperatures were generated using electric current passing through the wire, then the experimental results will be linearized to a constitutive model.

\section{CRYSTALLINE TRANSFORMATION}

When heating SMA, the martensite phase start to transform into austenite phase at austenite start temperature $T_{A s}$, when the temperature reaches austenite finish temperature $T_{\mathrm{Af}}$, the phase transformation is completed. In the case of cooling the alloy behaves with an opposite way, but it starts to transform into martensite at a different temperature $\mathrm{T}_{\mathrm{Ms}}$ and completes the transformation at another different temperature $\mathrm{T}_{\mathrm{Mf}}$. Also in case of changing the stress at a fixed temperature the alloy undergoes the same crystalline transformation, increasing the stress is the same as cooling the alloy and decreasing the stress is the same as heating the alloy. These transformation temperatures are functions of the stress where the larger the stress, the higher the transformation temperature. Usually the internal crystalline transformation diagram is constructed by the stress-strain curves tested at different temperatures. We will use the electrical current instead of the material temperature as the control parameter of the crystalline transformation. This helps in establishing the transfer function of the control system, because it will help to connect the output, the amount of the dissipated energy, directly to the input, the electrical current. Also it will reduce the effort which shall be done in measuring the temperature of the very thin SMA wire. 


\section{HYSTERESIS LOOP}

Figure 1 shows, schematically, the loading and unloading curve, stress-strain curve, of a SMA wire tested at electrical current (Amperes) higher than $A_{A f}$ (Austenite finish Ampere), causing a temperature higher than $T_{A f}$ (Austenite finish temperature). As the SMA is loaded at $A>A_{A f}$ from the stress-free stage, $O$, the stress-strain curve initially follows the straight line $(O D)$ with the slope of $E_{A}$ (Young's modulus of the austenite phase). Then it follows the straight line (DA) with the slope $E_{A M}$ (Young's modulus of the austenite to martensite transformation phase). Upon further loading, it follows a gradual straight line above point A where the curve becomes steep in a slope of $E_{M}$ (Young's modulus of the martensite phase) which equals approximately $E_{A}$. above point $A$, the SMA is under an elastic deformation with $100 \%$ martensite phase until it is yielded at the yield stress $\left(\sigma_{y}\right)$. When the stress is over $\sigma_{y}$, the $100 \%$ martensite phase of the SMA undergoes plastic deformation by a dislocation gliding mechanism.

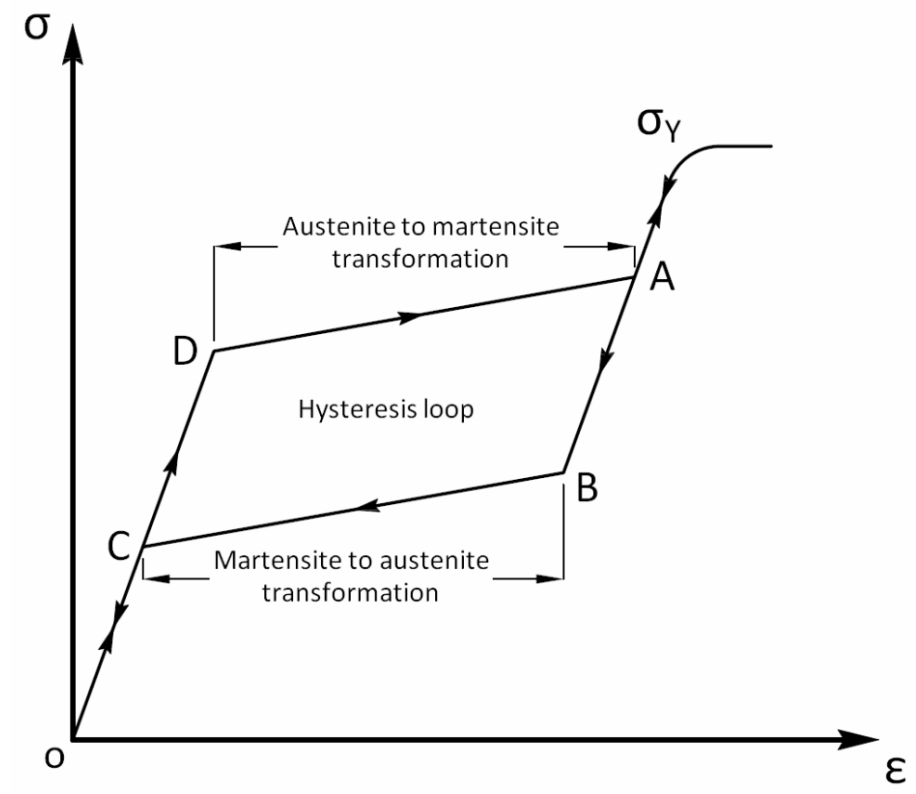

Fig.1. Stress-strain curve for shape memory alloy.

When unloading before yielding the material, the stress curve will follow the straight line $(A B)$ and continues through line $(B C)$ with slope $E_{M A}$ (Young's modulus of the martensite to austenite transformation phase) which equals approximately $E_{A M}$. The unloading beyond point $C$ follows the elastic deformation path (EO) to the origin $(O)$. The super-elastic loop ABCD (Hysteresis loop) represents the energy dissipated per unit volume during the loading and unloading cycle. The area and the slopes of the hysteresis loop depend on the value of the electric current as shown later.

\section{TESTING DEVICE}

A testing device was needed to perform a tensile test at different current values, but we faced two problems: 


\section{1) Crimping the SMA wire}

Normal specimen in the tensile test has two diameters; the larger is for crimping and the smaller is for testing, that enables us to cause the higher stress in the test length and the lower stress in the crimping side, but testing SMA wire with a constant diameter would cut the wire at the crimping area because it would suffer the higher stress (combined normal and shear stresses).

The high hardness of the SMA and the good surface finish of the SMA wire disable good crimping. Also Electrical insulation shall be provided by the crimp to insulate the wire, electrically, from the device body.

SMA wire manufacturer provides many designs of wire crimps, but these designs cannot withstand the high load that causes an ultimate stress in the wire without slipping. Also these designs are electric conductors.

We needed another crimp that can solve these problems, so we designed a perfect crimp, after many failed designs. This crimp (Shown in figure 2) made of hard wood (American beech wood) with a counter-sunk wood screw (size M2) to hold the SMA wire inside the crimp and conduct the electrical current to the wire. A cyanoacrylate adhesive was added to give the bond high strength.



Fig.2. Wooden crimp with holding screw. 
The perfection of this crimp comes from its ability to cause equal stress distribution whether along the test length or the crimping length. This was proved when many of the specimens were cut, almost, in mid of the test length.

\section{2) Measuring the small readings of the elongation and the load}

The need to apply a small load and to read small elongations can be achieved by using a new idea for a tensile testing machine. The new concept is to apply a known elongation instead of the known load and to read the corresponding carrying load instead of the elongation.

\section{Testing Device Anatomy}

Upper part; which is a gearbox (worm-worm-gear with ratio 1:60) with a hand wheel connected to a power screw that moves up and down according to the rotation of the hand wheel. This power Screw is rigidly connected to metal chunk (typical $1 / 2$ " drilling machine chunk) that holds firmly the SMA wire crimp.

Lower part; which consists of a metal chunk (typical to the upper part), rigidly connected to a $15 \mathrm{Kg}$ metal mass. This mass is resting on a digital weighing scale which is resting on an adjustable table. The selected digital weighing scale is using a strain gauge to minimize the deflection of the lower chunk (Figure 3).

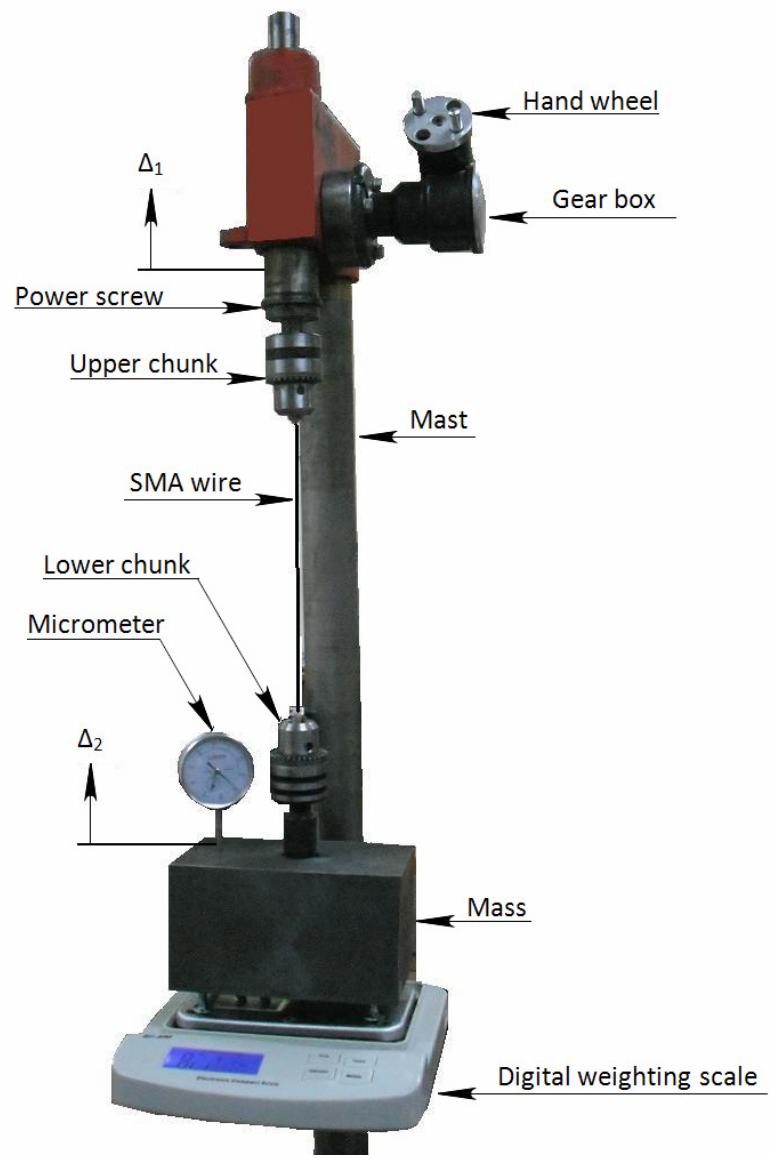

Fig.3.Testing Device Anatomy. 


\section{EXPERIMENT PROCEDURES}

1) Preparing specimen with certain length, by using 2 crimps and SMA wire of length $150 \mathrm{~mm}$ for the test length to be $100 \mathrm{~mm}$.

2) Fixing each crimp in the upper and the lower chunks.

3) Aligning the verticality of the SMA wire by using spirit level from front and side.

4) Resetting the digital weighing scale.

5) Raising the upper chunk slowly by the hand wheel (every $1 / 4$ revolution gives $0.35 \mathrm{~mm}$ ) before the weighing scale starts to measure in negative values.

6) Applying the desired electric current to the terminals of the SMA wires, the wire will shrink and the weighing scale will measure a negative values which is the load carried by the SMA wire.

7) Releasing the load on the wire by releasing the hand wheel till the weighing scale measure a zero value.

8) Measuring the new length, current-activated length $L_{A}$ of the wire by subtracting the movement of the upper chunk from the original length.

9) Starting to apply an elongation step and recording the corresponding load value.

10) Generating Stress-Strain curve for each Electric current.

Engineering strain can be calculated as following:

$$
\varepsilon=\frac{\Delta_{1}-\Delta_{2}}{L_{4}}
$$

But

$$
\Delta_{2} \cong 0 \quad \text { w.r.t. } \quad \Delta_{1}
$$

Then

$$
\varepsilon=\frac{\Delta_{\text {un }}}{L_{A}}
$$

Engineering stress can be calculated as following:

Since the volume of the wire is constant,

$$
\begin{gathered}
D_{A}=D_{\odot} \sqrt{\frac{L_{0}}{L_{A}}} \\
\sigma=\frac{4 \times F \times g}{1000 \times \pi \times D_{A}^{2}} \quad(M P a)
\end{gathered}
$$




\section{EXPERIMENTAL RESULTS}

58 experiments were done and the experiments show that the $\mathrm{Ni}-\mathrm{Ti}$ wire behaves in four different ways in four ranges of the electrical current:

\section{Electrical Current Lower than 600mA (Figure 4).}

- Loading: the material elongates elastically with $\mathrm{E}=20 \mathrm{GPa}$ till it reaches strain value 0.065 before starting to behave plastically.

- Unloading before reaching $\sigma_{y}$ the material recovers its length with elasticity modulus $\mathrm{E}=30 \mathrm{GPa}$.

- This behavior is not dependent on the electrical current for this range.

Because of the difference between elasticity modulus in both the loading and the unloading cases, there is about 0.02 unrecovered strain. This strain can be recovered by heating the material to a temperature higher than $\mathrm{T}_{\mathrm{Af}}$.

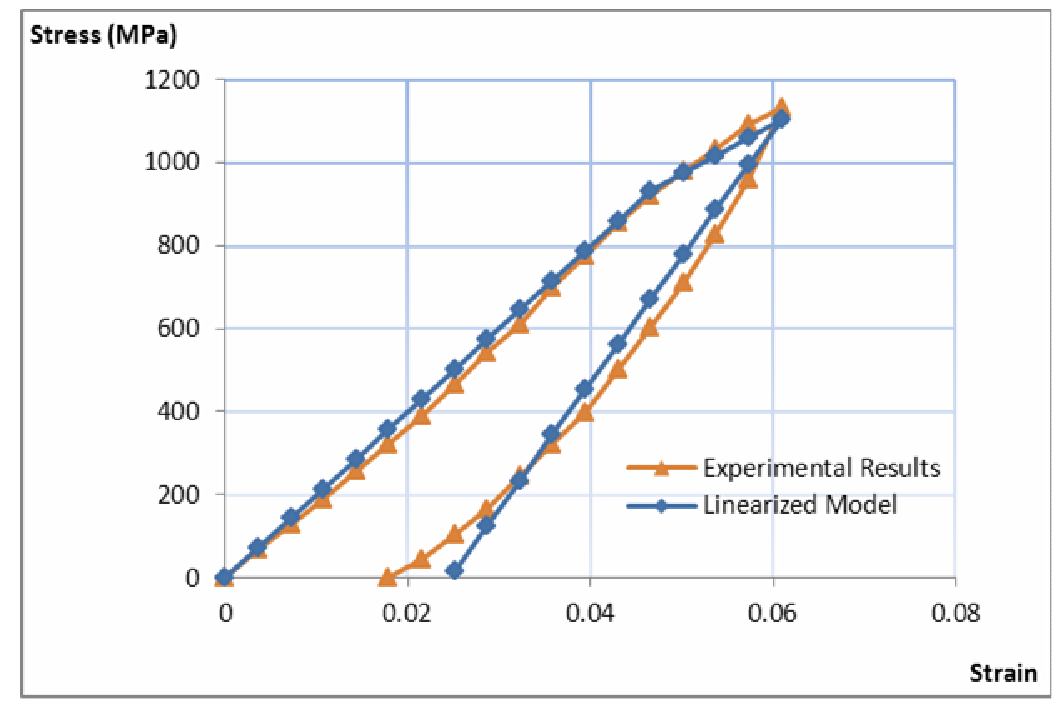

Fig.4.Loading and unloading stress-strain curve at $500 \mathrm{~mA}$.

\section{Electrical Current between $600 \mathrm{~mA}$ and 1.2 A (Control Range) (Figure 5).}

- Loading: the material elongates with elasticity modulus $E_{A}$ till it starts the transformation to martensite phase at certain strain, which depends on the electrical current. During the transformation, the Pseudo-elastic behavior of the SMA is clear. The material elongates with elasticity modulus $\left(E_{A M}=4.5\right.$ $\mathrm{GPa}$ ) till all the material becomes in martensite phase, then the stress curve increases gradually to $\sigma_{y}$ with the elasticity modulus $\mathrm{E}_{M}$ where $\mathrm{E}_{M} \approx \mathrm{E}_{\mathrm{A}}$.

- Unloading: the material returns with the same slope $E_{M}$ till it starts transformation to Austenite phase, then the material follows the transformation modulus $\mathrm{E}_{\mathrm{MA}}$ where $\mathrm{E}_{\mathrm{MA}} \approx \mathrm{E}_{\mathrm{AM}}$. 




Fig.5.Loading and unloading linearized stress-strain curve at electrical current between $600 \mathrm{~mA}$ and $900 \mathrm{~mA}$.

- It was found that the electrical current affects the shape of the hysteresis loop, as it affects the strain values at which the phase transformation occurs. The relation between the current and both of the strain values are shown in (Fig. 6).

- At $1000 \mathrm{~mA}$, a jump happens to the SMA behavior, where the strain, at which transformation from martensite to austenite occurs, downs from 0.07 to 0.03 to cause the loop to close at the free stress point (Fig. 6). Another jump in the slopes of the hysteresis loop, where $E_{A}$ and $E_{M}$ increase from 25 Gpa to 30 $\mathrm{GPa}$, and also to the transformation elasticity modulus $\mathrm{E}_{\mathrm{AM}}$ and $\mathrm{E}_{\mathrm{MA}}$ increase from $4 \mathrm{GPa}$ to $7.5 \mathrm{GPa}$ (Fig. 5).

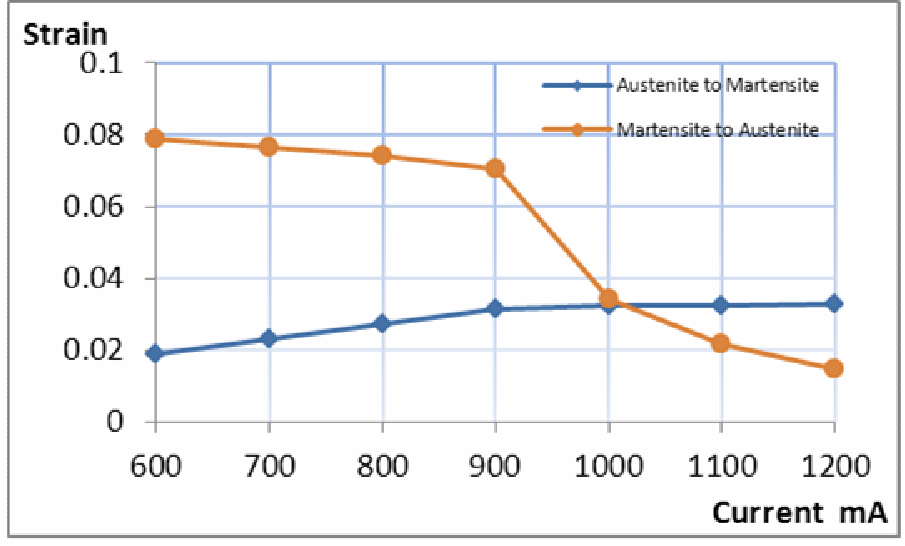

Fig.6.Transformation strain VS current.

- The area of the hysteresis loop (dissipated energy per unit volume), in this range, is decreasing linearly with respect to the electrical current (Fig. 7). 


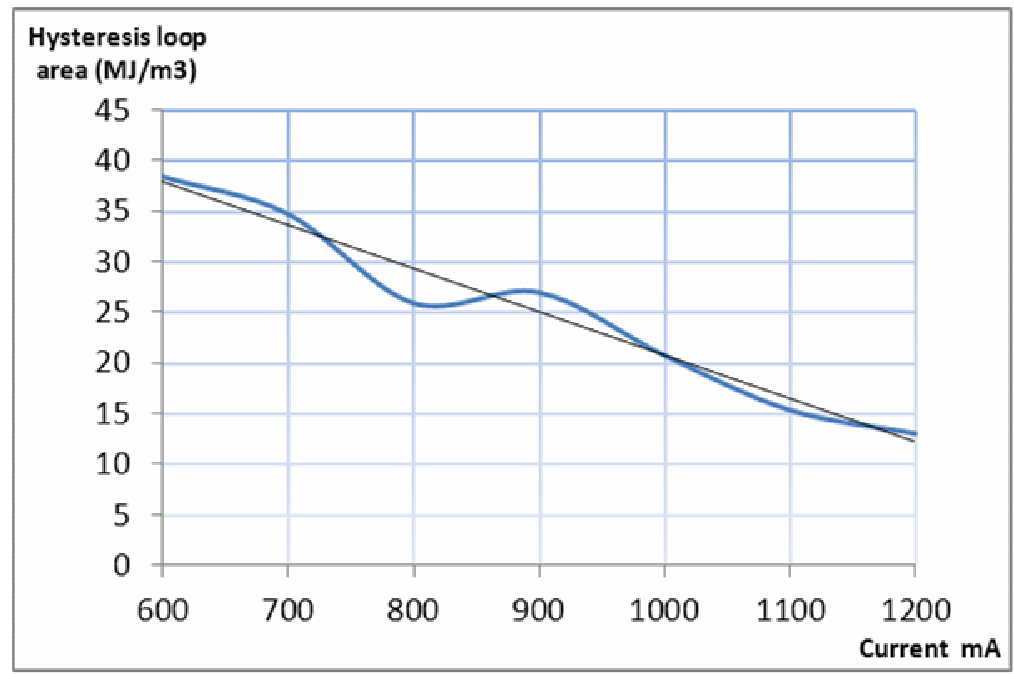

Fig.7. hysteresis loop area VS current.

- Experiments show that for all current values, there is an unrecovered length, residual strain, (Fig. 8). This residual strain can be recovered by reheating the wire, which agrees with Tanka [7].

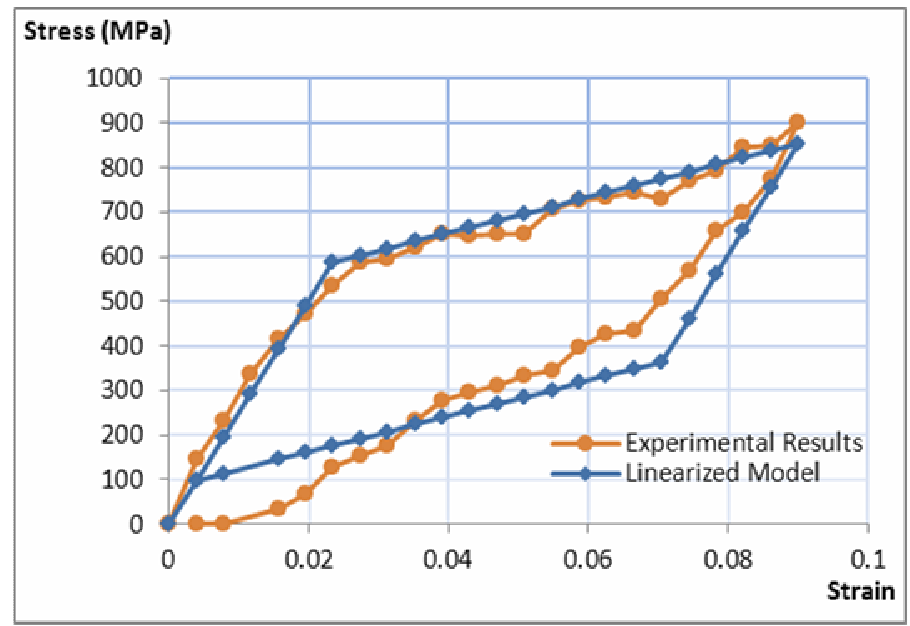

Fig.8. stress-strain curve for $800 \mathrm{~mA}$ showing an unrecovered length after unloading

\section{Electrical Current Higher than 1.2 A (Saturation Range) (Figure 9).}

- In this range, the hysteresis loop is very narrow and does not change with the current; this can be explained as follows: the heat generated by these high currents is always keeping the material in the austenite phase despite of any applied stress, i.e. the material becomes in austenite phase and does not undergo any crystalline transformation to martensite phase.

- When applying the electrical current to the wire, it starts to shrink and carries the load till it reaches $5000 \mathrm{~g}$ then the carried load relaxes to $700 \mathrm{~g}$ in 2 minutes and oscillates around this value.

- The wire becomes red when subjected to electrical currents higher than 2.6 A. 


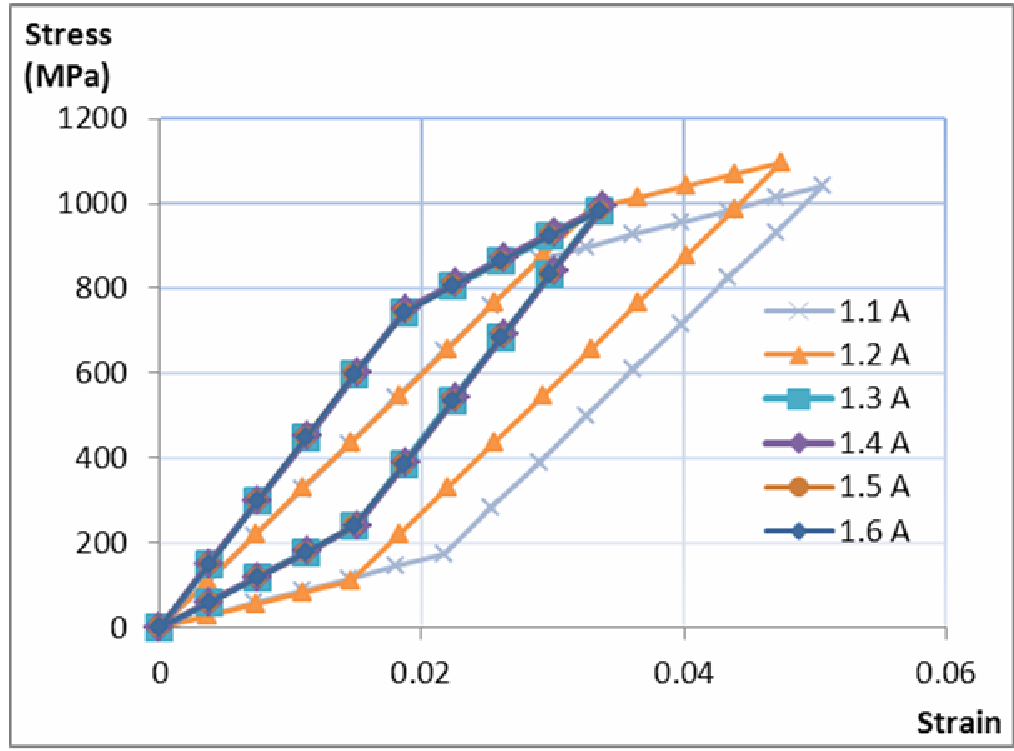

Fig.9.stress strain behavior of electric currents higher than $1.2 \mathrm{~A}$ compared to $1.1 \mathrm{~A}$ and $1.2 \mathrm{~A}$.

\section{Resilience}

Resilience of a SMA wire is the absorbed energy, elastically, during loading the wire. It is calculated for electric current range from $300 \mathrm{~mA}$ to $1600 \mathrm{~mA}$ as following:

$$
\text { Resilience }=\int_{0}^{z_{y}} \sigma d s
$$

The super-elastic behavior of SMA is found clearly in the electric current range from $600 \mathrm{~mA}$ to $900 \mathrm{~mA}$, this super-elastic behavior increases the resilience of SMA from $40 \mathrm{MJ} / \mathrm{m}^{3}$ to $130 \mathrm{MJ} / \mathrm{m}^{3}$ (Fig. 10).

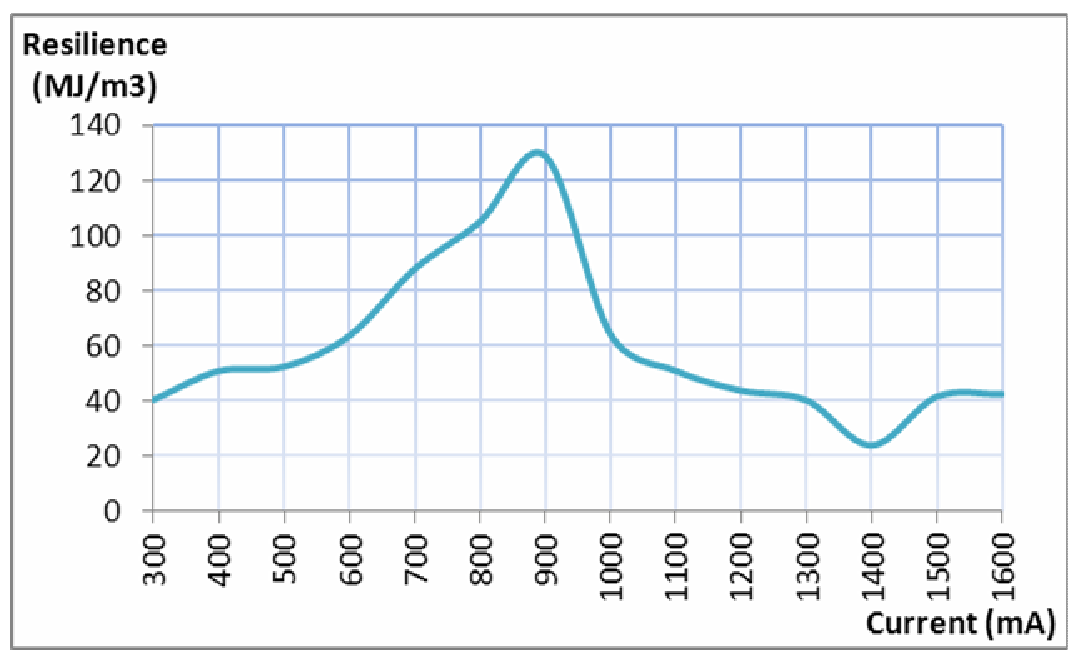

Fig.10. Resilience of SMA VS electric current. 


\section{Ambient Temperature Effect.}

Since the purpose of the electric current is to generate heat inside the SMA wire. Then the wire temperature, which affects the crystalline transformation, is not affected by the electric current only but also the amount of heat transfer to the surrounding environment. This heat transfer is dependant on the ambient temperature. Loading and unloading of an SMA wire was done at two different ambient temperatures. The first was done in the mid of November 2011 (ambient temperature $=25^{\circ} \mathrm{C}$ ) and the other was done in the mid of January 2012 (ambient temperature $=15^{\circ} \mathrm{C}$ ), Figure 11 shows the effect of this change on the hysteresis loop. Extra work is needed to study the effect of the ambient temperature.

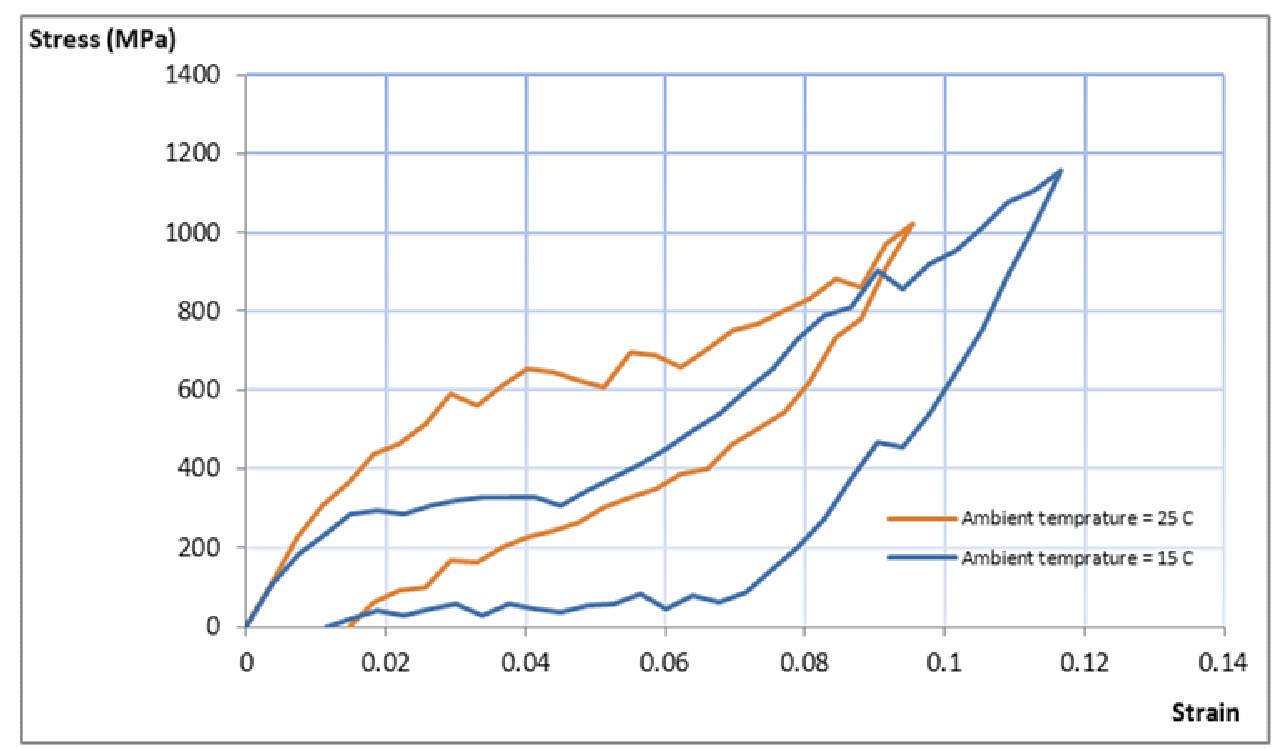

Fig.11. Stress-strain curve for $600 \mathrm{~mA}$ at two different ambient temperatures.

\section{CONCLUSIONS AND FUTURE WORK}

- Electric current can be used as a good controller to control the dissipated energy according to the changes of the vibration energy.

- Extra work is needed to study the effect of the ambient temperature.

- Extra work is needed to study the effect of repeating the loading-unloading cycle on the unrecovered length and the behavior of SMA wires

\section{REFERENCES}

[1] Mel Schwartz, "Smart Materials", CRC Press, 2008.

[2] Chang L C and Read T A, "Plastic deformation and diffusionless phase change in metals-the gold-cadmium beta phase Trans", AIME J. Met., 191 47-52, (1951).

[3] Buehler W J, Gilfrich J V and Wiley R C, "Effect of low-temperature phase change on the mechanical properties of alloys near composition TiNi", J. Applied Physics, No. 34 1475-7, (1963). 
[4] Otsuka K and Wayman C M, "Shape Memory Materials", Cambridge, Cambridge University Press, (1998).

[5] P. Thomson, G. J. Balas and P. H. Leo, "The Use of Shape Memory Alloys For Passive Structural Damping", IOP Pub;ishing Ltd, journal of Smart Material, (1995)

[6] Roger Fosdick and Yohannes Ketema, "Thermal Effects on the Vibration Damping Properties of Shape Memory Alloys", Journal of Intelligent Material Systems and Structures, Vol. 20, (2009).

[7] K. Tanaka, "A Phenomenological Description on Thermomechanical Behavior of Shape Memory Alloys", Journal of Pressure Vessel Technology, (MAY 1990). 